\title{
Funding for mental health research: the gap remains
}

\section{Helen Christensen PhD, MPsychol(Hons) Director \\ Philip J Batterham
MPH, PhD, Postdoctoral Research \\ Fellow ${ }^{\top}$ \\ Ian B Hickie \\ Executive Director}

Patrick D McGorry PhD

Executive Director

Philip B Mitchell

AM, MD, FRANZCP. Head

Jayashri Kulkarni $\mathrm{PhD}$,

Director $^{5}$

1 Centre for Mental Health Research, Australian National University, Canberra, ACT.

2 Brain and Mind Research Institute, University of Sydney,

Sydney, NSW.

3 Orygen Youth Health University of Melbourne

Melbourne, VIC.

4 School of Psychiatry, University of

New South Wales,

Sydney, NSW.

5 Monash Alfred Psychiatry

Research Centre,

Monash University

Melbourne VIC.

helen.christensen@ anu.edu.au

MJA 2011; 195: 681-684 doi: 10.5694/mjal0.11415
P.

ressure is mounting for reform in Australia's mental health sector. ${ }^{1-4}$ Mental health research is recognised as playing a role in developing effective, innovative approaches to treatment, intervention and primary health care.

Mental health researchers in Australia are concerned that their contribution is being thwarted, because research funding from the National Health and Medical Research Council (NHMRC) is lower than that awarded to other National Health Priority Areas (NHPAs), including cancer, cardiovascular disease, diabetes, injury, arthritis and asthma. There is also a perception that such research funding differentially supports certain domains of mental health research, such as substance misuse, to the detriment of other fields such as psychosis, depression, anxiety and eating disorders, which are critical targets of mental health reform. There is concern that funding is not being directed to high-priority research targets.

Researchers also believe that the "success" rate for mental health grants may be lower than for other research categories. A potential reason for the lower success is that the quality of mental health research in Australia is perceived to be poorer than that of other medical and health specialties. There is now a need to reassess mental health research funding from 2001 to 2010, to examine the contributions to different disorder subtypes, assess success rates within granting schemes, and compare mental health contributions internationally.

Our article aims to examine the levels and growth rates of absolute funding to mental health research over the past 10 years compared with other NHPAs, and the relative rate of mental health funding compared with other NHPAs, by taking disease burden into account. We predicted that NHMRC project grants in mental health would show the same success rates as grants from non-mental health research areas. Finally, we

Objectives: To examine the levels and growth rates of absolute funding to mental health research from 2001 to 2010, compared with other National Health Priority Areas (NHPAs), and the relative rate of mental health funding compared with other NHPAs, by taking disease burden into account. The quality of Australian research in mental health was also examined using objective indicators of research strength.

Design and setting: Retrospective analysis of levels of funding overall and as a function of mental health domains using data from the National Health and Medical Research Council, with and without adjustment for burden of disease. A keyword analysis was used to assess the success rate of mental health project grant applications. Objective indicators of the quality of Australian mental health research were sought from citation indicators.

Main outcome measures: Funding for mental health research relative to disease burden; funding according to disease category; project grant success rates.

Results: Using actual and adjusted figures, mental health research received a lower proportion of health funding than other NHPAs, including cancer, diabetes and cardiovascular disease. Research projects into substance misuse and autism were proportionately better funded than those in anxiety, depression or schizophrenia. A significant proportion of mental health research funding was awarded to research into ageing. Citation data indicated that mental health research in Australia performed better than research in neuroscience, clinical medicine, microbiology, and pharmacology and toxicology, and at a comparable level to immunology research, despite poor levels of funding.

Conclusions: Low levels of funding for mental health research appear to be largely attributable to low capacity. Mental health research in Australia is of high quality, and efforts are needed to build capacity.

examined the quality of Australian research in mental health using Institute for Scientific Information (ISI) citation data, which provide external and objective indications of research strength.

\section{Methods}

NHMRC funding data for 2001-2010 were obtained from the NHMRC research funding datasets. ${ }^{5}$

Ethics approval was not sought because data were retrieved in deidentified form from available databases. Funding as a function of disease burden was calculated using methods described elsewhere. ${ }^{6,7}$

To determine success rates of grant funding for mental health compared with other health research areas, we examined the titles of all 2010 project grants, and classified them into "mental health" or "other". While the title of 2010 successful grants is public information, unsuccessful NHMRC grant information, including project titles, is confidential. Therefore, we validated the use of keywords to distinguish mental health grants from others in the successful NHMRC grants from 2010.

The successful mental health grants were distinguished from successful non-mental health grants using the first two research keywords and first two health keywords. With assistance from the NHMRC, this set of keywords was applied to the full set of successful and unsuccessful grants to determine the extent to which mental health keyworded grants were successful, relative to the full set; and the extent to which certain categories of mental health funding were successful, relative to other categories. By categorising the selected keywords, we classified grants into "mental health", "ageing" and "substance abuse".

To examine the quality of mental health research in Australia using international benchmarks, we examined the independent ISI indicator website. We determined the strength of citations of Australian research in 


\section{Proportion of funding provided to the seven National Health Priority Areas, 2001-2009*}

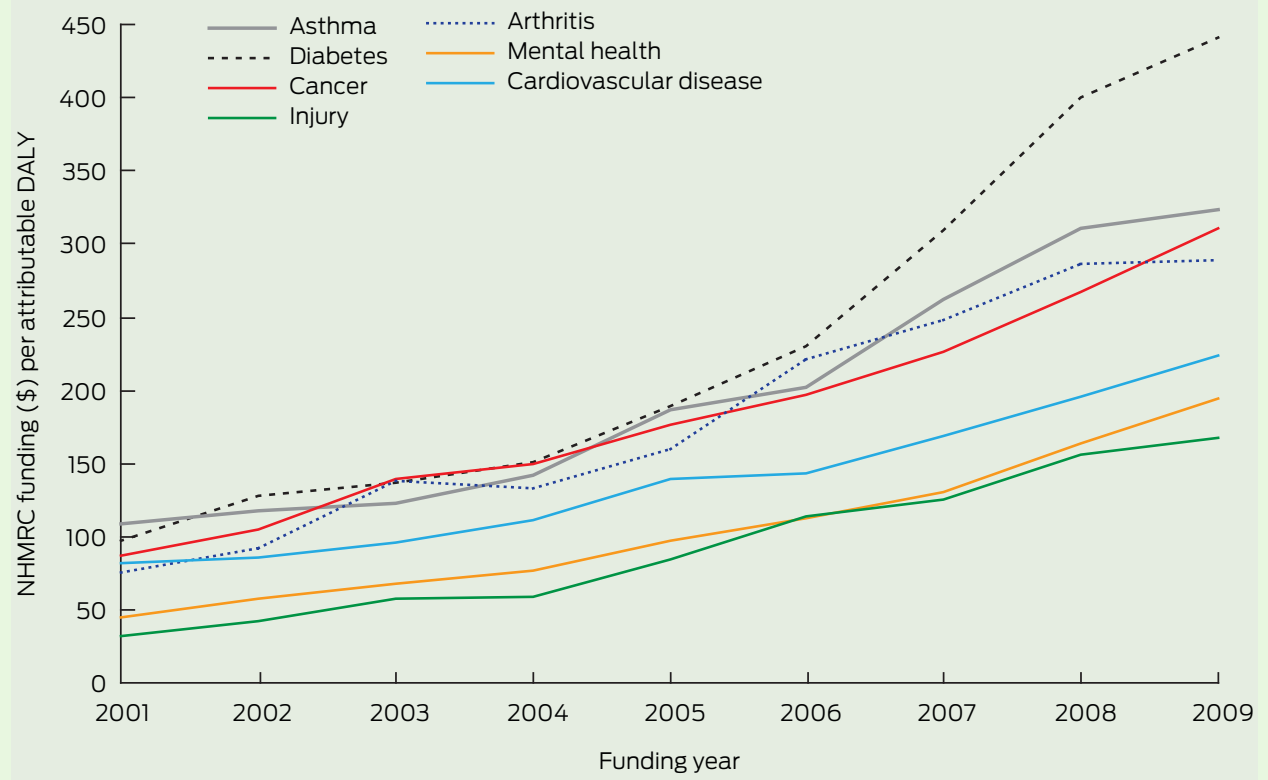

NHMRC = National Health and Medical Research Council. DALY = disability-adjusted life-year. * For the purpose of burden-ofdisease analyses, depression, psychosis and anxiety research were combined, because the NHMRC combines depression and psychosis research and the Australian Institute of Health and Welfare DALY estimates combine depression with anxiety.

\section{Project funding adjusted for DALYs, 2001-2009}

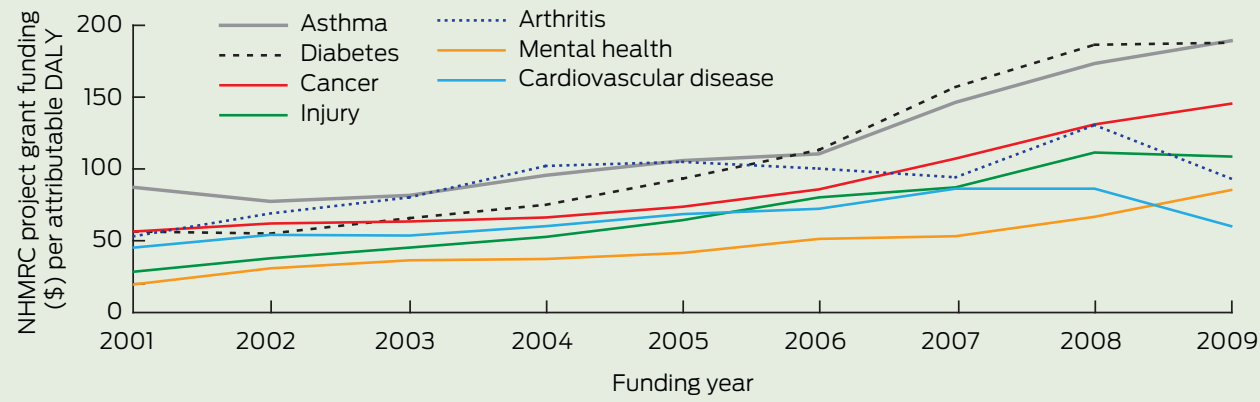

DALY = disability-adjusted life-year. NHMRC = National Health and Medical Research Council.

\section{Funding per DALY, by mental health research category, 2001-2009}



DALY = disability-adjusted life-year. ADHD = attention deficit hyperactivity disorder. NHMRC = National Health and Medical Research Council. the fields of psychiatry and psychology, neuroscience and behaviour, immunology, social sciences, clinical medicine, microbiology, and pharmacology and toxicology. Citation ranks were also standardised by national population.

\section{Results}

\section{Research funding relative to disease burden}

Mental health research receives lower levels of funding than cardiovascular disease and cancer research (about $9.5 \%, 21.7 \%$ and $14.9 \%$, respectively, in 2009). However, when adjustments are made for burden of disease (Box 1 ), the areas of diabetes, asthma, cancer, arthritis and cardiovascular disease all receive proportionately more research dollars per attributable disability-adjusted life-year (DALY) ${ }^{7}$ than does mental health. Relative to other conditions, diabetes had the largest increase in research funding from 2001 to 2009 (see Box 2 for data on project grants).

\section{Research funding by mental health category}

Box 3 outlines the funding awarded within mental health categories from 2001 to 2009, inclusive. Substance misuse and autism did proportionately better per DALY than eating disorders, attention deficit hyperactivity disorder, or anxiety, depression and schizophrenia. Although it is difficult to interpret trends, funding to suicide and eating disorders research does not appear to have increased over the past 10 years, despite the nearly threefold increase in medical research funding overall. Up to $6 \%$ of mental health funding consisted of grants for research into ageing in any one year.

We examined data for project grants in 2010 separately. There was no increase in funding for project grants within the mental health category from 2009 to 2010. Total NHMRC funding for project grants was $\$ 415$ million. Of this, $\$ 44.1$ million was for 86 mental health research projects (including topics marginally related to mental health, eg, ageing and cognition). This figure is an increase of $\$ 8.5$ million over 2009 


\begin{tabular}{|c|c|c|c|c|c|c|}
\hline Research field & $\begin{array}{l}\text { Number } \\
\text { of articles }\end{array}$ & $\begin{array}{l}\text { International } \\
\text { article ranking* }\end{array}$ & $\begin{array}{c}\text { Total } \\
\text { citations }\end{array}$ & $\begin{array}{c}\text { International } \\
\text { citation ranking* }\end{array}$ & $\begin{array}{l}\text { Citations } \\
\text { per capita }\end{array}$ & $\begin{array}{l}\text { Rank of citations } \\
\text { per capita }\end{array}$ \\
\hline Psychiatry, psychology & 11959 & 5 & 124922 & 6 & 0.0055 & 9 \\
\hline Social sciences & 20442 & 4 & 91138 & 4 & 0.0040 & 8 \\
\hline Neuroscience, behaviour & 8248 & 11 & 137295 & 12 & 0.0061 & 16 \\
\hline Immunology & 4864 & 8 & 110779 & 8 & 0.0049 & 8 \\
\hline Clinical medicine & 67057 & 9 & 1003105 & 9 & 0.0445 & 14 \\
\hline Microbiology & 4864 & 11 & 88596 & 9 & 0.0039 & 12 \\
\hline Pharmacology, toxicology & 4018 & 14 & 52961 & 14 & 0.0024 & 16 \\
\hline
\end{tabular}

* The national ranking of Australia compared with all other countries, based on the number of articles or citations listed on Essential Science Indicators data for each research domain.

funding levels, but as a proportion of NHMRC project funding, it is a decrease from $11 \%$ of all funding in 2009 to $10.6 \%$ in 2010.

Eighteen dementia-specific projects (a special funding scheme within the NHMRC) accounted for $22.5 \%$ of the estimated mental health research funding to commence in 2011. After excluding these from the estimate, $\$ 34.2$ million (8.2\%) was won by mental health research, a drop in funding of $\$ 1.3$ million from 2009, representing a decrease of $2.8 \%$.

\section{Project grant success rates}

The success rate of all project grants in 2010 was $22.6 \%$ (757 of 3345 applications were funded), and mental health projects were funded at the rate of $22.7 \%$. Project grants within the core mental health subcategory achieved a $22.1 \%$ success rate, the ageing subcategory achieved $23.5 \%$ and substance misuse achieved 30.4\%.

\section{Australian mental health research quality}

Box 4 shows how Australian scientific research has performed in terms of quantity (number of articles) and quality (citations), compared with the rest of the world. The data on papers and citations come from the ISI Essential Science Indicators website (http://wokinfo.com/products_ tools/analytical/essentialscience indicators/).

Although the bulk of mental health research is included in the field of psychiatry and psychology, some is categorised as neuroscience and behaviour, social sciences or clinical medicine. In psychiatry and psychology, and social sciences, Australia's performance appears to be outstanding (in the top five internationally) in terms of both quantity and quality of research publications, outperforming immunology, clinical medicine and microbiology.

Similar rankings for fields are achieved if rankings are calculated based on rates of citations per publication, which is another common approach to ranking. Even after adjusting for population (when smaller European countries tend to do better), Australian mental health research performs very well, achieving success comparable to immunology.

By these measures, and assuming that the ISI categories converge reasonably well with the NHMRC mental health categories, mental health research in Australia would be considered to be producing a high quantity and quality of research relative to the rest of the world and performing better than a number of other scientific disciplines.

\section{Discussion}

The proportion of funding from the NHMRC to mental health research has not increased in line with other NHPAs over the past 10 years. Given that base rates were the lowest in 2001, funding to mental health research relative to burden remains the lowest across all NHPAs. Within mental health categories, addiction and substance misuse and autism were well funded, relative to disease burden, a difference that existed at the beginning of 2001 .

The analysis of the data on 2010 project grants suggests that the rate of success in obtaining funding for mental health research is commensurate with that in other areas of the NHMRC, but that some domains of research are better funded than others within this category. For example, it is clear that substance misuse has a better grant success rate than core mental health disorders.

We attribute this differential effect to greater capacity for research into substance misuse, particularly through government-funded research centres, although there may be other explanations, such as higher quality of grant writing. It is also clear from the international benchmarking that the quality of mental health research in Australia is likely to be no worse than that of other areas of research.

Based on our analysis, it is clear that mental health research does not receive the same level of funding support as other research areas such as cancer and diabetes, a conclusion already reached by Mitchell and colleagues. ${ }^{6}$ In the United States, 13\%$15 \%$ of National Institutes of Health funding goes to mental health and drug and alcohol research, and research into ageing, a percentage that has been stable since $2001 .^{8}$ Even if funding for research into ageing is excluded from the US figures, $10 \%-$ $11 \%$ of US funding goes to the areas covered by the NHMRC mental health category. In short, two indicators (funds per DALY and international funding levels) indicate that mental health research funding is relatively low in Australia.

NHMRC mental health project grants enjoy the same level of success as non-mental health grants, suggesting that the quality of grant applications is commensurate with other areas. International benchmarks also support the strength and quality of success of mental health research. Australia is the fifth-ranked country in overall numbers of psychology and 
psychiatry articles, and sixth-ranked in citations.

Our analysis shows little evidence that the criteria used to fund mental health research is biased for project grants. However, bias may be an issue with the "newer" NHMRC schemes (those introduced over the past 4-5 years), such as Australia Fellowships, Development Grants, Centres of Research Excellence, and Translating Research into Practice Fellowships. In 2010, 54 of these grants were offered, but mental health researchers were unsuccessful in every one of these schemes. ${ }^{9}$ This poor success rate could arise by chance; as a result of poor scientific quality; because of low application rates by mental health researchers; due to other unknown factors; or because of bias in ranking, given the evidence of high international success.

\section{Improving funding for mental health research}

Our analysis suggests that the main barrier to mental health research funding is capacity. As noted by Mitchell and colleagues, ${ }^{6}$ the Wills report recommended that the NHMRC engage in building national workforce capacity. ${ }^{10}$ It also recommended that the NHMRC could specifically allocate personnel support funds to under-resourced areas to build up workforce capacity. ${ }^{6}$ Based on the data we have from 2009 and
2010, this recommendation has not resulted in any substantial change in workforce capacity in mental health research. In this respect, it is pleasing to see that in the Australian Budget of May 2011, \$26.2 million of NHMRC money was earmarked for special mental health research initiatives. ${ }^{11}$

There are several limitations to our analysis of NHMRC grant funding. Inaccuracies may exist in the secondary datasets; the DALY estimates used to weight the funding are specific to Australia; the keyword validation process was applied only to the 2010 data; not all research schemes could be analysed because public datasets were not sufficiently detailed; and, finally, it is not clear which NHMRC grants were awarded funds from supplementary monies.

In conclusion, there has been no "narrowing of the gap" over the past 10 years in the proportion of funding provided to mental health research. If we assume that NHPAs should be equally prioritised, the failure to narrow the gap indicates the need for action over the next decade.

Acknowledgements: We thank Saraid Billiards and Marcus Nicol, from the NHMRC, for making data available. Competing interests: No relevant disclosures. Received 2 Dec 2010, accepted 27 Jul 2011.

1 Department of Health and Ageing. Towards a national primary health care strategy. Canberra: DoHA , 2008. http://www.health.gov.au/ internet/main/publishing.nsf/Content/ D66FEE14F736A789CA2574E3001783C0/\$File/ DiscussionPaper.pdf (accessed Nov 2011).
2 Department of Health and Ageing. National Mental Health Report 2010. Canberra: DoHA 2008. http://www.health.gov.au/internet/main/ publishing.nsf/content/8C20A89EAC527C40CA 2577EE000F6E01/\$File/rep10cov.pdf (accessed Nov 2011).

3 National Health and Hospitals Reform Commission. A healthier future for all Australians, final report June 2009. Canberra: NHHRC, 2009. http://www.health.gov.au/internet/nhhrc/ publishing.nsf/Content/nhhrc-report (accessed Nov 2011).

4 Australian Medical Association. Mental health position statement. Canberra: AMA, 2011. http:// ama.com.au/node/6524 (accessed Nov 2011).

5 National Health and Medical Research Council. NHMRC research funding dataset 2001-2010. Canberra: NHMRC, 2010. http://www.nhmrc.gov. au/grants/dataset/rmis/index.htm (accessed Nov 2011).

6 Mitchell RJ, McClure RJ, Olivier J, Watson W. Rational allocation of Australia's research dollars: does the distribution of NHMRC funding by National Health Priority Area reflect actual disease burden? Med J Aust 2009; 191: 648-652.

7 Australian Institute of Health and Welfare. The burden of disease and injury in Australia 2003. Canberra: AlHW, 2007. http://www.aihw.gov.au/ publication-detail/?id=6442467990 (accessed Nov 2011).

8 National Institutes of Health Office of Budget. $\mathrm{NIH}$ history of congressional appropriations, fiscal years 2000-2010. http://officeofbudget.od.nih. gov/pdfs/FY11/Approp.\%2OHistory\%20by\% 20IC\%20\%28FINAL\%29.pdf (accessed Nov 2011).

9 National Health and Medical Research Council. Outcomes of funding rounds. Canberra: NHMRC 2011. http://www.nhmrc.gov.au/grants/rounds/ index.htm (accessed Nov 2011).

10 Wills PJ. The virtuous cycle. Working together for health and medical research. Canberra: Commonwealth of Australia, 1998. http://www. health.gov.au/internet/main/publishing.nsf/ Content/hmrsr.htm (accessed Nov 2011).

11 Australian Government. Budget 2011-12: delivering better hospitals, mental health and health services. Canberra: Commonwealth of Australia, 2011. http://budget.australia.gov.au/ 2011-12/content/download/glossy_health.pdf (accessed Nov 2011). 